\title{
DIÁLOGOS BINACIONALES SOBRE LOS RETOS PARA DOCUMIENTAR LA(S) VIOLENCIA(S) CONTRA MUJERES INDÍGENAS EN MÉXICO Y CANADÁ
}

BINATIONAL DIALOGUES ON THE CHALLENGES TO DOCUMENT THE (S) VIOLENCE (S) AGAINST INDIGENOUS WOMEN IN MEXICO AND CANADA

\author{
DIÁLOGOS BINACIONAIS SOBRE OS DESAFIOS PARA DOCUMENTAR A (S) \\ VIOLÊNCIA (S) CONTRA MULHERES INDÍGENAS NO MÉXICO E CANADÁ
}

Vivian Jimenez-Estrada, Professora Associada do Departamento de Sociologia

Universidade de Algoma vivian.jimenez-estrada@algomau.ca

Canadá

Norma Don Juan Pérez

Promotora de direitos humanos, educadora popular e pesquisadora social Coordinadora Nacional de Mujeres Indígenas CONAMI México yoloyotl@gmail.com México

Patricia Torres Sandoval Rede Nacional de Advogados Indígenas dpattyt@hotmail.com México

Dolores Figueroa Romero

Doctora en Sociologia Centro de Investigaciones y Estudios Superiores en Antropología Social Dolores.figueroa@ciesas.edu.mx México

\section{Resumen}

Este artículo está basado en un diálogo que cuestiona la producción de conocimiento sobre la violencia de género que afecta a las mujeres Indígenas de Abya Yala y de la Isla Tortuga. Analizamos críticamente que las políticas institucionales para la erradicación de las violencias no han incorporado el análisis de los efectos de la violencia colonial y estructural que afecta a las mujeres Indígenas y sus pueblos. Es importante revertir esta omisión a través de propuestas de 
documentación desde una perspectiva interseccional y reflexiva de los contextos. Consideramos que no será posible responder a los reclamos de justicia de género -tanto en el Sur como en el Nortesi no interpelamos el racismo y la colonialidad que media de la relación entre el Estado y pueblos Indígenas, y que constituye la experiencia de violencia contra hombres y mujeres Indígenas.

Palabras clave: Violencia colonial, violencia de género, mujeres Indígenas, documentación cualitativa y cuantitativa, interseccionalidad

\begin{abstract}
This article is based on a dialogue that questions the production of knowledge on gender violence that affects Indigenous women from Abya Yala and Turtle Island. We aim to critically analyze how institutional policies for ending violence have not incorporated an analysis of the effects of colonial and structural violence that affects Indigenous women and their Nations. It is thus important to address this gap through the documentation of these violences from an intersectional and reflexive perspective. We believe that it will not be possible to respond to the demands for gender justice both in the South and in the North - if we do not challenge the racism and coloniality that mediate the relationship between the State and Indigenous Peoples, and that constitutes the experience of violence against both, Indigenous women and men.
\end{abstract}

Keywords: Colonial violence, gender violence, Indigenous women, qualitative and quantitative documentation, intersectionality

\title{
Resumo
}

Este artigo se baseia em um diálogo que questiona a produção de conhecimento sobre a violência de gênero que atinge as mulheres Indígenas de Abya Yala e da Ilha Tortuga. Analisamos criticamente que as políticas institucionais para a erradicação da violência não incorporaram a análise dos efeitos da violência colonial e estrutural que afeta as mulheres Indígenas e seus povos. É importante reverter essa omissão através de propostas de documentação em uma perspectiva interseccional e reflexiva dos contextos. Acreditamos que não será possível responder às demandas por justiça de gênero - tanto no Sul como no Norte - se não desafiarmos o racismo e a colonialidade que medeiam as relações entre o Estado e os povos Indígenas e que constituem a experiência da violência contra homens e mulheres Indígenas.

Palavras-chave: Violência colonial, violência de gênero, mulheres Indígenas, documentação qualitativa e quantitativa, interseccionalidade 
omos un grupo de activistas $\mathrm{y}$ académicas - Indígenas $^{1} \mathrm{y}$ aliadas - que desde hace muchos años participan $\mathrm{y} / \mathrm{o}$ apoyan a movimientos Indígenas de las Américas. Nuestro colectivo se compone, por un lado, de investigadoras de varias universidades y centros de investigación en Canadá y México, y por otro, de lideresas Indígenas de la Coordinadora Nacional de Mujeres Indígenas de México (CONAMI) y mujeres Anishnaabe del colectivo Indigenous Women's AntiViolence Task Force (IWAVTF). Nuestra red de colaboración es acuerpado por la Asociación Canadiense de Estudios sobre Latinoamérica y el Caribe (CALACS, por sus siglas en inglés), el Centro de Investigaciones y Estudios Avanzados en Antropología Social (CIESAS), y el Grupo de Trabajo de Estudios Indígenas. $^{2}$ La diversidad de geografías políticas y experiencias de vida que alimentan esta conversación surgió en 2017 a raíz de una iniciativa para reflexionar virtualmente en un foro transcontinental sobre violencia colonial

\footnotetext{
${ }^{1}$ Como autoras de este ensayo, y colectivo de aliadas, queremos referir y utilizar el término Indígena en mayúsculas, aún contraviniendo las reglas gramaticales del español por una decisión política de honrar y mostrar respeto por las compañeras activistas y madres que enriquecen estos planteamientos y pensamientos, así como para reconocer la soberanía de los pueblos a los que pertenecen.

2 El grupo de trabajo sobre estudios Indígenas/Indigenous Studies Working Group fue creado en el 2013, y es un espacio encuentro de académicos canadienses y latinoamericanos miembros de CALACS interesados en temas de indigenidad y derechos en las Américas para dialogar sobre problemáticas, políticas y procesos sociales relacionadas a los pueblos (https://can-latam.org/working-groups/indigenousstudies).

${ }^{3}$ El Foro Virtual 2017 sobre Violencia contra las mujeres en las Américas, fue financiado por una beca de Conexión Social -Social Sciences and Humanities Council SSHRC-Canadá).
}

y estructural contra mujeres Indígenas de las Américas $^{3}$ auspiciado por CALACS (GUIMONT, FIGUEROA, JIMENEZESTRADA y RICE, 2020). A partir del foro virtual otras experiencias de diálogo $\mathrm{y}$ reflexión -presencial y virtual-se han dado lugar, ya sea en talleres, encuentros y visitas a campo. En particular este ensayo rescata las ideas vertidas en una mesa redonda organizada en el marco del Congreso de la Asociación Americana de Estudios de América Latina (LASA) ${ }^{4}$ donde hablamos de las experiencias de mujeres Indígenas organizadas para atender, abordar $\mathrm{y}$ documentar las violencias (en plural) desde las perspectivas locales e interseccionales de las participantes (JACOBS, 2013; ECMIA, 2013; CRENSHAW, 1993).

La mesa redonda contó con la participación de lideresas y académicas de Canadá y México, todas autoras de este ensayo, para dialogar sobre cómo tejemos la colaboración entre nosotras, cómo

En este espacio virtual se profundizó sobre el uso de términos como genocidio, etnocidio y genocidio cultural para considerar las geografías de la violencia y los contextos coloniales donde se dan desplazamientos, despojo y violaciones graves de los derechos humanos de las mujeres indígenas (GUIMONT, FIGUEROA, JIMENEZESTRADA Y RICE, 2020). La participación de CONAMI en este diálogo virtual fue generosa y amplia, y marcó el inicio de la colaboración con colegas académicas y organizaciones de mujeres indígenas de Canadá que en adelante se expandió.

${ }^{4}$ Mesa redonda: "Retos para documentar el feminicidio en zonas indígenas en México y Canadá desde una perspectiva interseccional" organizado por Dolores Figueroa y Vivian Jimenez Estrada, con la participación de Norma Don Juan y Patricia Sandoval Torres. Congreso de la Asociación Americana de Estudio de América Latina (LASA), 16 de mayo, modalidad virtual. 
conceptualizamos la violencia, qué acciones que emprendemos para denunciarla y prevenirla, y cuales son las estrategias de resistencia en lo local. Para nosotras ha sido importante dimensionar hasta qué punto las geografías determinan los contextos de enunciación de nuestro trabajo político, la experiencia colectiva de violencia, y cuales son los términos $\mathrm{y}$ referentes culturales para nombrar la discriminación e historias de daño. La distancia geográfica entre el Norte y el Sur nos hacen más conscientes de que las culturas Indígenas comparten una condición de abandono y negación (ALTAMIRANOJIMENEZ， 2013， HERNÁNDEZ y HUTCHING, 2019). Rechazamos el modelo civilizatorio occidental porque sabemos los efectos dañinos que ha causado la modernización y el borramiento de "otras" las culturas y formas de vivir (SEGATO, 2014; JACOBS, 2013; COULTHARD, 2014). Sabemos que la tarea de descolonizar nuestro pensamiento y formas de actuar con respecto a la investigación y la producción del conocimiento es un trabajo político y ético constante; por ello nuestra colaboración trata de responder de manera reflexiva al compromiso de realizar cada una, por nuestro lado, la tarea de desmontar y cuestionar los privilegios y preconcepciones que pre-condicionan en esta relación (REGAN, 2010). Por una lado, como académicas buscamos descolonizar nuestras formas de hacer investigación y entablar diálogos cognitivos donde la extracción de conocimiento no se de lugar; por otro lado, como lideresas Indígenas partimos del posicionamiento político de que la erradicación de la violencia sólo podrá darse como resultado de desmontar la noción de "víctima" que históricamente se les ha sido asignado a la mujer Indígena negándole un rol activo y diligente en transformar sus comunidades.

Genocidio, etnocidio y feminicidio son algunos de los términos que se han empleado para nombrar distintas formas de exterminio que dañan y causan pérdidas irreparables en las comunidades indígenas de las Américas (GUIMONT, FIGUEROA, JIMENEZ-ESTRADA Y RICE, 2020). El exterminio histórico y silencioso de los pueblos Indígenas se ha dado en contubernio con el Estado y a través de procesos de cristianización, modernización y desarrollo (BRANDFORD BURNS, 1983; BOURGEOIS, 2018) Más aún, la dominación de los pueblos se ha logrado a través de la instrumentalización de la violencia contra la mujeres Indígenas, deshumanizado y mancillando su cuerpo como parte consustancial del proceso de colonización (SMITH y ROSS, 2004; SIMTH, 2005). Es por ello que, ante la violencia contemporánea, las comisarías de 
policía locales, departamentos nacionales de estadísticas, y ministerios de justicia no han sido consecuentes en prevenir el exterminio sistemático de las mujeres y no dimensionar estas prácticas desde el racismo institucional que implica. En nuestra perspectiva ningún planteamiento y mecanismo estratégico de erradicación de la violencia contra mujeres Indígenas pueden obviar la participación de actores institucionales ya que ellos deben ser partícipes de los mecanismos de desmantelamiento del racismo y la ceguera conceptual, política y metodológica.

Una parte significativa de nuestras conversaciones transnacionales se han avocado en hacer legibles los contextos de las políticas de estado con respecto a procesos de asimilación y aniquilación cultural. Pensamos reflexivamente en las diferencias históricas que determinan la relación estado-pueblos Indígenas y los mecanismos discriminatorios contra mujeres indígenas en los dos países son relevantes para ubicar nuestra relación de colaboración y el trabajo de documentación de la violencia. En contexto canadiense el proceso de búsqueda de justicia para las mujeres Indígenas inició con la investigación nacional

\footnotetext{
${ }^{5}$ Las escuelas residenciales en el contexto de Norteamérica son instituciones para la población Indígena creadas exprofeso por la administración colonial para asimilar de manera forzosa, a niños/as Indígenas en las formas occidentales. Las escuelas eran dirigidas por congregaciones religiosas $y$ funcionaban en todas las provincias y territorios canadienses, excepto en la Isla del Príncipe Eduardo, Nuevo Brunswick y Terranova. Las escuelas residenciales operaron en Canadá entre los años 1831 y 1996. Los niños/as fueron enviados por la fuerza a estos internados, a una tierna edad, y en la mayoría
}

del sobre el asesinato y desaparición de mujeres y niñas indígenas (IMMIW\&G) y el proceso de reconciliación nacional por los impactos intergeneracionales de las escuelas residenciales $^{5}$ en población indígena. ${ }^{6}$ En el caso mexicano, la ruta de búsqueda de justicia para mujeres Indígenas ha estado ligada históricamente a la defensa del territorio, y en las últimas dos décadas, a las políticas institucionales de prevención de la violencia de género y feminicida impulsadas por el movimiento feminista que surgieron en el marco de la lucha contra el crimen organizado. En ambos casos se tratan de políticas y discursos que enfatizan la atención de las violencias extremas sin tomar en cuenta procesos de racialización y despojo de largo aliento, que para el entendimiento de la violencia contra mujeres Indígenas requiere de un acercamiento más cuidadoso de varios tipos de discriminación y vulnerabilidades que se concatenan acumulativamente en el tiempo (SCHEPER-HUGHES y BOURGOIS, 2004).

$$
\text { Epistemológicamente, creemos }
$$
importante plantear la necesidad de movilizar una crítica a la construcción del conocimiento sobre violencia de género que restringen su

\footnotetext{
de los casos no regresaban a sus territorios de origen hasta ser jóvenes adultos. La pérdida del idioma y las costumbres, los efectos de abuso sexual y físico, además del sometimiento a experimentos médicos sin su consentimiento y las muertes debido al mal cuidado han sido las bases de la demanda en contra de este genocidio. https://indigenouspeoplesatlasofcanada.ca/article/history-ofresidential-schools/

6 https://reconciliationcanada.ca/your-voice-your-canada/
} 
marco explicativo a la relación de dominación víctima-victimario, obviado lecturas sociales más amplias. En función de este vacío queremos posicionar el trabajo de conceptualización de las violencias (en plural) que han desarrollado las compañeras indígenas del Enlace Continental de Mujeres Indígenas de las Américas (ECMIA), quienes en el seno de foros internacionales han facilitado espacios de discusión conceptual entre lideresas de todo el continente. El movimiento de las mujeres Indígenas de las Américas han optado por hablar de sus experiencias de violencia en plural porque la violencia contra las mujeres y las niñas, adolescentes y jóvenes Indígenas es de variada naturaleza, y ello incluye la violencia política, social, económica, espiritual, simbólica, racial, física y estructural; que puede darse específicamente contra ellas o en general contra los pueblos de los que forman parte, en el espacio público y comunitario implicando actores estatales y no estatales, o en el espacio privado. El análisis propuesto de la violencia busca abarcar todos los modos posibles de percibirla (ECMIA, 2013). Siendo consecuentes con esta mirada incluyente y holística, colectivos de mujeres Indígenas como CONAMI se han dado a la tarea de documentar todo tipo de violencias, incluyendo las que se generan por la imposición de megaproyectos, la presencia del crimen organizado o la violencia institucional en sus expresiones más racistas, como es la muerte materno-infantil. Este ejercicio no es necedad o falta de conocimiento especializado para hacer investigación social, sino un esfuerzo orquestado para la erradicación de las violencias, la justicia y la sanación personal y colectiva. Se trata de una apuesta por la experimentación metodológica y conceptual que busca rescatar la complejidad de los contextos de la vida de las comunidades, de los pueblos y de las mujeres Indígenas.

Los diálogos de este ensayo los hemos organizado en cinco secciones: (1) En la sección inicial vamos ubicar las geografías de exclusión y estereotipos racializantes de los cuerpos de mujeres Indígenas en Canadá y México; (2) en la segunda sección hablaremos de las estadísticas de violencia feminicida contra las mujeres Indígenas donde queremos mostrar la sobre representación y la invisibilidad de ellas en los discursos generalistas; (3) en la tercera sección hablaremos de las iniciativas que nuestros colectivos desarrollan alrededor de la ética y los enfoques de análisis para documentar, visibilizar, contabilizar las violencias en plural; (4) la cuarta sección tratará de los espacios de interpelación y diálogo con el Estado y otros actores institucionales; y por último (5) concluiremos con una reflexión sobre el trabajo activista y la documentación en tiempos del COVID. 
Geografías de exclusión y estereotipos racializantes de la población indígena en México y Canadá

En esta sección queremos referir a las geografias sociopolíticas y mecanismos sociales de exclusión que determinan y que enmarcan los retos de trabajo activista de las lideresas Indígenas de la CONAMI y Baawaating IWAVTF. Entendemos las geografías de la exclusión como producto de la colonización que ha discriminado espacial y socialmente a los pueblos Indígenas arrebatándoles sus territorios pero también su identidad y conocimientos. Los EstadosNación de México y Canadá se han constituido en razón de la sistemática violación de territorios y de mujeres Indígenas; esta violencia física, política y simbólica está "... normalizada, incrustada en el tejido social de las relaciones coloniales" (HOLMES, HUNT y PIEDALUE 2014: 551) que caracterizan la vida social e institucional en ambas latitudes. Los cuerpos y territorios ubicados en estos espacios de exclusión evolucionan de hecho en un reino de impunidad; como no sirven al progreso de la Nación, no están amparados por el Estado y sus normas de derecho, y están condenados a la violencia. Estos espacios son físicos, marginados, pero también creados por diferentes políticas económicas, culturales o sociales. En palabras de Kuokkanen “ ... como el segmento más pobre y desfavorecido de la sociedad, las mujeres Indígenas están en el extremo receptor no solo de violencia física o sexual, sino también de violencia estructural, política y económica, todo lo cual refuerza y reproducirse unos a otros" (2008: 220).

Los territorios Indígenas de México se concentran en el noroeste, centro y sur del país. "Regiones de refugio" es como la antropología ha llamado a las geografías de aislamiento en las cuales la población Indígena ha sido contenida después de sobrevivir procesos de despojo, empobrecimiento y desplazamiento forzado por décadas (AGUIRRE BELTRÁN, 1967). Al paso de los años las montañas con tierras poco cultivables o zonas bajas, aisladas y de difícil acceso se han convertido en los territorios que les han permitido a las poblaciones Indígenas escapar de la explotación y la asimilación a la cultura nacional mestiza y los proyectos de modernización desarrollista. En informe del Consejo Nacional de Evaluación de las Políticas de Desarrollo Social (CONEVAL) correspondiente al decenio 2008-2018 refleja los siguientes indicadores de la pobreza social y material de la población Indígena: cerca una de cada cuatro personas Indígenas se encuentran en situación de pobreza extrema, en contraste con la población no Indígena, en la que una de cada veinte personas se encuentra en esa 
situación. Este informe define la pobreza como resultado de una combinación de varios factores entre los que destacan condiciones de infraestructurales de vivienda y comunicación, falta de acceso a servicios sociales, índices de desempleo, bajos ingresos, tasas de mortalidad y flujos migratorios temporales. Combinando la dimensión espacial y densidad demográfica el informe indica que cinco estados de la república concentran en un $80 \%$ población indígena viviendo en pobreza extrema (Chiapas, Oaxaca, Guerrero, Durango y San Luis Potosí), y siete estados más tienen población Indígena viviendo en algún tipo de carencia social de entre el $65 \%$ y $80 \%$ (Veracruz, Puebla, Morelos, Estado de México, Jalisco e Hidalgo). El 50\% de la población indígena reside en localidades rurales de los cuales cerca de 3.4 millones viven en pobreza extrema. ${ }^{7}$ En adición a lo anterior, apuntaríamos que la población Indígena mexicana sigue residiendo en zonas rurales, en poblados y localidades de menos de 2, 500 habitantes. ${ }^{8}$ En la actualidad la tranquilidad social de los territorios de refugio están cruzados y diezmados por la imposición de megaproyectos, por la presencia del crimen organizado, la

\footnotetext{
${ }^{7}$ Fuente: estimaciones del CONEVAL con base en el Modelo Estadístico 2015 para la continuidad del MCS-ENIGH y la Encuesta Intercensal 2015.

${ }^{8} \mathrm{https} / / /$ www.coneval.org.mx/Medicion/MP/Documents/Pobr eza_Poblacion_indigena_2008-2018.pdf

${ }^{9}$ De acuerdo a los censos nacionales uno de cada tres Indígenas habita zonas urbanas (INEGI, 2010) e incluso se han definido
}

corrupción de militares atraídos por distintas prácticas de enriquecimiento ilícito (HERNÁNDEZ, 2019). En muchos sentidos el despojo y la violencia siguen, y se incrementan con la precarización de la economía campesina que expulsa a familias Indígenas de manera constante a los espacios urbanos. ${ }^{9}$ Se estima que cerca del $30 \%$ de la población Indígena vive en entornos urbanos (Mendoza, 2010) pero su presencia es invisible en las estadísticas y por lo tanto en diagnósticos y políticas publicas focalizadas a la atención de pueblos Indígenas así como políticas de atención para combatir la violencia contra las mujeres.

Por su parte en Canadá el proceso de desplazamiento y contención geográfica de las naciones indígenas de dio primeramente a raíz de la firma de tratados políticos entre la corona inglesa y las naciones indígenas permitiendo la creación del sistema de reservas en áreas de poco interés económico y productivo para los colonos blancos (ABORIGINAL HEALING FOUNDATION, 2010; RCAP, 1996; TRC 2015). De acuerdo a la Comisión Real de Pueblos Indígenas / Royal Commission on Aboriginal Peoples (RCAP, por sus siglas en Inglés) la creación de reservas para el uso de

55 zonas metropolitanas, como es el caso de la zona metropolitana de la Ciudad de México donde la diversidad de grupos étnicos la hace una región de numerosas lenguas y riqueza cultural, aunque también se caracteriza por elevados índices de marginación y numerosas tareas pendientes en el terreno del acceso a la justicia (MENDOZA, 2010, p. 7). 
los Pueblos Indígenas, reconocidos por el gobierno federal bajo sus condiciones identitarias en la 'Ley de Indios / Indian Act, ${ }^{10}$ redujeron el tamaño de sus territorios con el objetivo de brindar la 'civilización' occidental a los pueblos indígenas a través de la agricultura, el cristianismo y una forma de vida sedentaria basada en la propiedad privada (1996). Según la Ley de Indios, el gobierno canadiense definió una reserva como tierra que ha sido reservada (no separada) por el gobierno federal para el uso y beneficio de una banda Indígena tal como lo prescribe esta ley. Es importante señalar que las tierras de las reservas todavía se clasifican como tierras federales, los Pueblos Indígenas no tienen escrituras y que en muchos casos no hay Acuerdos en donde los Pueblos Indígenas han cedido su territorio. Debido al contexto complejo de las geografías en donde viven, los Pueblos Indígenas necesitan desesperadamente proveedores, unidades y suministros de atención médica. Hay 96 comunidades Indígenas remotas en Canadá, y mientras que la mayoría se encuentra en los territorios del Noroccidente, Nunavut y Yukon, es importante notar que dentro del norte de Ontario, la población Indígena comprende el 17\% del total de la población, y ahí se encuentran 109 de las 127 reservas

\footnotetext{
${ }^{10}$ Indian Act es el nombre en inglés, o 'Ley para Indios' en español, es un estatuto legal canadiense que norma a nivel federal todos los asuntos concernientes a la población indígena, formas de gobierno y reservas indígenas. Contiene prescripciones sobre mecanismos de otorgamiento, reconocimiento y trasmisión intergeneracional del status
}

registradas con el gobierno federal (STATISTICS CANADA, 2017). Específicamente en el territorio de Baawaating residen la primera nación Batchewana, que se divide en cuatro comunidades/reservas: Rankin, Obadjiiwan, Goulais y White Fish Island. ${ }^{11}$

Cuando se combina la constante lucha por tierra, territorio frente al rápido declive de cultura y aumento de la pobreza material, una mayor incidencia de problemas de salud subyacentes, condiciones de vida abarrotadas y poco saludables, falta de agua limpia, sistemas de alcantarillado defectuosos y acceso limitado a la atención médica, se puede ver por qué los pueblos Indígenas que viven en las reservas son tan vulnerables a epidemias y pandemias. De la misma, a través de la 'Ley para Indios' (Indian Act) se materializó el desmontaje del sistema económico, político, social y cultural tradicional que daba a las mujeres un rol importante y estimado en sus comunidades, reemplazándolo con un sistema patriarcal, cristiano y dominado por el sentido de controlar la naturaleza y el cuerpo de las mujeres. Es por ello que este sistema ha causado el declive del estatus y el reconocimiento de la importancia de las

\footnotetext{
indígena. Data desde el 1876, y ha tenido varias modificaciones. Disponível em: https://www.thecanadianencyclopedia.ca/en/article/indianact. Accesso 18 jun 2020.

${ }^{11} \mathrm{https} / / /$ batchewana.ca/communities/
} 
contribuciones de las mujeres Indígenas y de personas de géneros diversos que ha contribuido a su deshumanización.

Añadiremos que guiados por construcciones sociales cristianas-puritanas de lo que significa ser mujer Indígena, la sociedad canadiense colona impuso procesos de asimilación cultural -como las escuelas residenciales- que causaron cambios profundos sociales, espirituales y económicos en las sociedades Indígenas generalizando estereotipos deshumanizantes de las mujeres Indígenas ligados a dos imaginarios: 1. la de la mujer noble y buena, y 2. la de consumo sexual y de cuerpo desechable (RAZACK 2016; PALMATER 2015). Esta racialización de género como cuerpos sexualizados con una moralidad supuestamente laxa, naturaliza las consecuencias de la violencia infligida, al tiempo que borra el contexto social de marginalización, despojo y pobreza que obliga a las mujeres abandonar sus territorios de origen y/o a vivir en áreas menos seguras. Esto es sumamente importante, ya que estos tropos guían las acciones para con las mujeres Indígenas de la Norteamérica anglófona.

Un caso emblemático en Canadá para la ilustrar lo explicado en el párrafo anterior es la muerte de Cindy Gladue, una mujer Indígena Cree quien ejercía como sexoservidora y fue asesinada por su 'cliente' de raza blanca, habiendo sufrido desangramiento por el uso de un arma blanca en sus genitales. El "cliente" fue perdonado por el crimen y se ha argumentado que se introdujeron mitos y estereotipos racistas $\mathrm{y}$ sexistas en los procedimientos que, probablemente, desviaron al jurado del análisis cuidadoso del consentimiento que exige la ley canadiense (PALMATER, 2015; SUPREME COURT OF CANADA, 2020). Los procedimientos jurídicos lograron seguir violentando a Cindy Gladue cuando, en su caso, la fiscalía decidió introducir la vagina mutilada de Cindy como prueba de la parte acusatoria sin consultar a la familia y sin reparar en el hecho que desmembraron su cuerpo. Lo que estos procedimientos legales tienen en común es que el intento detrás de la violencia ejercida, tanto por los agresores como durante procesos de justicia, están guiados por estereotipos que vemos del día a día en medios de comunicación, en textos, $\mathrm{y}$ en el lenguaje que se utiliza para describir y tratar a los pueblos Indígenas en general y mujeres en particular (RAZACK, 2016; IAAW y LEAF, 2019). En este sentido, recordemos que la representación nos permite mapear las ideologías dominantes a medida que circulan a través de la cultura y se reproducen como sitios para la interpelación de individuos en subjetividades específicas de género, clasificadas y racializadas. Sin embargo, la feminista Audre Lorde (1984) nos recuerda que es importante ir más allá de esto y analizar sociológicamente el colonialismo y sus efectos, en cómo ha 
patologizado, demonizado, denigrado y oprimido a los Pueblos Indígenas, así como el efecto sobre los que están en el "poder". Este análisis nos lleva a reconocer cómo los criterios geopolíticos y legales colonizadores limitan el reconocimiento de los espacios urbanos como territorios de violencias contra las mujeres Indígenas (BOURGEOIS, 2018). En México, particularmente las mujeres jóvenes Indígenas enfrentan una mayor vulnerabilidad al encontrarse fuera/lejos de su red de apoyo familiar/comunitaria por razones de educación y/o empleo (OEHMICHEN-BAZÁN, 2019).

En el caso mexicano existen de igual varios imaginarios nacionales que acallan la voz y la agencia de las mujeres Indígenas. El más persistente es la noción de víctima producto de falta de información, por la pobreza de sus condiciones de vida, y/o por ser presa de reglas sociales consuetudinarias patriarcales que violentan sus derechos (SIEDER y BARRERA, 2017; SEDOU, 2020). La victimización de la mujer indígena en las políticas públicas -desarrollistas y de prevención de la violencia doméstica- las reduce a ser receptoras silenciosa de programas o mecanismos de atención social que de manera preconcebida asume por parte de ellas una inadecuación, una falta de capacidades, un atraso cultural y comportamental que la hace copartícipe de su condición de opresión (MORA, 2017). El supuesto general que subyace en encuestas, reportes y diagnósticos institucionales sobre violencia sexual y doméstica es que las mujeres Indígenas mexicanas experimentan mayores niveles de violencia de pareja que las mujeres no Indígenas, debido a la prevalencia de normas y valores patriarcales tradicionales en sus comunidades, aunado a las condiciones de vida precarias. Este supuesto descalifica al mundo social comunitario, pues naturaliza la violencia como parte sustancial a ciertos tipos sociales de convivencia. Como lo expresa Norma Don Juan: "Hemos sido convertidas en propiedad de los hombres y de la sociedad, y así somos violadas en espacios públicos y privados [...] Quedamos en un estado de vulnerabilidad e invisibilidad" (18 de febrero, 2017, Foro Virtual/CALACS).

México no cuenta con una política de Estado ni sectorial dirigida a mujeres indígenas, aunque algunas dependencias de gobierno aplican un enfoque de trabajo intercultural que instrumentaliza mecanismos de consulta y/o de manera preferencial trabajan con organizaciones locales traductoras/mediadoras (BONFIL, DE MARINIS, ROSETE \& MARTINEZ, 2017, pp. 72). Hace diez años instituciones como el Instituto Nacional de Geografia y Estadística (INEGI), el Instituto de Salud Pública y la Comisión Nacional para el Desarrollo de los Pueblos Indígenas (CDI) tuvieron la iniciativa de elaborar encuestas que muestran datos que 
desglosan diferencias en la experiencia de violencia de mujeres -como la llamada la Encuesta Nacional sobre las Dinámicas de las Relaciones en los Hogares (ENDIREH) ha sido levantada en cuatro ocasiones. ${ }^{12}$ Esta encuesta aún cuando no hace desglose por etnicidad, espacialmente sugiere indicadores para ubicar la violencia comunitaria en territorios Indígenas. En específico la Encuesta de Salud y Derechos de las Mujeres Indígenas (ENSADEMI, 2008) reflejan indicadores sobre la experiencia de cuatro tipos de violencia: física, sexual, emocional, económica y en el campo de la salud, y la forma en cómo está organizada la información muestra una tendencia en interpretar los índices de las mujeres Indígenas anclados en los imaginarios y estereotipos a la mujer Indígena que llevan sugerir una condición de víctima silenciosa del poder intra-comunitario o de la administración de su fertilidad empezando por matrimonio forzado a tierna edad o la hipersexualización de sus cuerpos. Por ejemplo, estas inquietudes representan una parte importante de la experiencia de socialización de mujeres Indígenas oaxaqueñas del Istmo, donde hay un constructo social desde las narrativas de los visitantes y extranjeros antropólogos que han representado a las mujeres zapotecas como hiper-sexualidadas. De ahí que haya una

\footnotetext{
${ }^{12} 2003,2006,2001$ y 2016
}

mirada externa que ha exotizado la región, y sobre todo la sexualidad femenina y otras orientaciones e identidades sexuales (FIGUEROA ROMERO y HERNÁNDEZ, en prensa). Esto mismo pareciera que se está dando lugar en la frontera sur del país en estados como Chiapas donde observadores de derechos humanos han dado reportes de la existencia de redes de trata y una creciente industria del llamado etno-porno (ROJAS, 2020). Es pues que en ambos contextos se han dado, por un lado, políticas para administrar a la población indígena y a las geografías, ubicando y reubicando población desechable en regiones de riesgo o poco útiles al mercado (WRIGHT, 2013); y por otro, los imaginarios nacionales que invisibilizan y acallan la violencia estructural que aquella la vida de las mujeres Indígenas.

\section{Violencia extrema contra mujeres Indígenas en las estadísticas: entre la sobrerrepresentación y la invisibilidad}

El tema de la violencia de género y feminicida no es nuevo. En Canadá, en promedio, una mujer o niña es asesinada cada 2 días y medio según un primer informe emitido por el Observatorio Canadiense de Femicidio para la Justicia (CFOJA) y 
publicado por la Universidad de Guelph (2019) sobre las tasas nacionales de feminicidio. ${ }^{13}$ A pesar de que la población de mujeres y niñas Indígenas conforman 5\% de la población total, representan $36 \%$ de las estadísticas de mujeres desaparecidas y asesinadas (PALMATER 2015; NWAC 2010; GOBIERNO DE CANADÁ 2019). En el prefacio del reporte final de la Investigación Nacional sobre Mujeres y Niñas Indígenas Desaparecidas y Asesinadas se indica que es doce veces más probable que mujeres Indígenas sean víctimas de asesinato o desaparición que cualquier otra mujer en Canadá, y según Statistics Canada, entre 2001 y 2015, las tasas de homicidio de mujeres Indígenas fueron casi seis veces más altas que las de mujeres no indígenas (2019: 7). Estas tendencias a la sobre-representación de la población femenina Indígena en las estadísticas criminológicas canadienses se da también en otros aspectos, por ejemplo la Asociación de Mujeres Indígenas de Ontario estima en un $70 \%$ o $80 \%$ de las sexoservidoras en las calles de grandes urbes son indígenas, preocupantes indicadores que hablan de rezagos y prácticas discriminatorias de largo aliento. ${ }^{14}$ Las organizaciones de mujeres Indígenas de la Columbia Británica, Ontario y Quebec se han abocado a

\footnotetext{
${ }^{13}$ https://news.uoguelph.ca/2019/01/u-of-g-releases-firstannual-report-on-national-femicide-rates/

14 Ontario Native Women's Association, Sex Trafficking of Indigenous Women in Ontario (February 2016) at 5
}

documentar y co-relacionar los casos de desaparición y asesinato de niñas y jóvenes indígenas con prácticas nocivas como la trata sexual, pobreza urbana y migración campociudad; ello pensando en subsanar la falta de prestancia y diligencia que la Policía Real Montada muestra para documentar, investigar y sancionar lesiones contra mujeres Indígenas (BOURGEOIS，2018; GARCÍA DE MORAL, 2018).

En México las estadísticas elaboradas por organizaciones como ONU mujeres o el Observatorio Ciudadano Nacional del Feminicidio (OCNF) señalan que los asesinatos diarios de mujeres pasaron de $7 \mathrm{a}$ 10 en los últimos tres años. ${ }^{15}$ Los observatorios y grupos feministas abocados a contabilizar los feminicidios a nivel estatal y nacional realizan un importante trabajo de construcción estadística para poder dimensionar las tendencias y patrones de muertes violentas de mujeres, pero la tarea no es sencilla pues las fuentes de información oficial como el Instituto Nacional de Estadística (INEGI) y el Secretariado Ejecutivo del Sistema Nacional de Seguridad Pública (SESNSP) generan indicadores diferentes que no necesariamente son comparables y compatibles. Mientras que unas estadísticas son generadas a partir del

<http://www.onwa.ca/upload/documents/report-sextrafficking-of- indigenous-wom.pdf

${ }^{15} \mathrm{https}: / /$ www.jornada.com.mx/ultimas/sociedad/2020/03/05/o nu-feminicidios-en-mexico-crecieron-de-7-a-10-diarios-entres-anos-8647.html 
número de defunciones de mujeres, otras rescatan información de las fiscalías sobre carpetas de investigación de homicidios. Los homicidios dolosos y feminicidios son dos figuras penales bajo las cuales se catalogan las muertes violentas de mujeres y pueden variar de un estado a otro, por lo mismo no pueden ser contabilizados de maneras homogéneas en el país (DATA CÍVICA, 2019; ESTRADA, 2018). Debido a que las cifras oficiales sobre desaparición $\mathrm{y}$ violencias extremas contra mujeres no son desagregadas por etnia o raza, equipos estadísticos están implementando otras entrada de análisis estadístico como hacer cruces de variables de homicidios de hombres y mujeres en municipios indígenas $\mathrm{y}$ compararlo con los no indígenas tomando como referencia los municipios que el Instituto Nacional de Pueblos Indígenas (INPI) cataloga como indígenas por tener un porcentaje poblacional de más del $40 \%$. Los resultados son impactantes, entre 2001-2016 ocurrieron 267,910 homicidios en México; de ese universo 40,145 (17\%) se dieron en regiones y municipios Indígenas, de los cuales 35, 282 fueron homicidios de hombres y 4,863 de mujeres (FRÍAS, en prensa). El doce por ciento de las muertes violentas en zonas Indígenas son de mujeres, según cifras compuestas de estadísticas vitales,

\footnotetext{
${ }^{16} \mathrm{https}: / /$ www.eleconomista.com.mx/politica/Dos-de-cada-10mexicanos-se-asumen-indigenas-20181212-0049.html

${ }^{17} \mathrm{https}$ ://amapolaperiodismo.com/los-feminicidios-masanunciados-los-de-la-montana-de-
}

mortalidad, INEGI y proyecciones de población de CONAPO. En el país hay catalogadas 25 regiones Indígenas que corresponden a 623 municipios (25\%). ${ }^{16}$

Como puede apreciarse existe una heterogeneidad de los indicadores estadísticos oficiales de los cuales se puede desprender un aproximado de los índices de mujeres indígenas que son víctimas de violencia en México. Otra dimensión a mencionar, es la zona gris de sub-registros de fallecimientos de mujeres en zonas rurales que acontecen en el silencio de la precariedad y de la lejanía, donde quizás los únicos aludidos son las autoridades comunitarias. El Centro de Derechos Humanos de la Montaña Tlachinollan de la Montaña de Guerrero reporta la rutinaria desatención por parte ministerios públicos de casos que reportan agresiones físicas, sexuales y verbales a mujeres comunitarias; agresiones que son subestimadas y que concluyen en feminicidios que no son debidamente procesados. $^{17}$

En función de los elementos mencionados es que las estadísticas formales sobre mujeres Indígenas desaparecidas $\mathrm{y}$ asesinadas en México son prácticamente inexistentes y apuntalan a un mayor problema que exige la necesidad de crear bases de datos confiables que reflejen la violencia feminicida 
y estructural contra mujeres Indígenas y sus pueblos (CONAMI, 2017). Como colectivo, entendemos que los datos duros no son una panacea para aliviar este urgente tema, sin embargo, estamos conscientes de la necesidad de generar estos datos para promover conciencia sobre las raíces sistémicas que generan y reproducen las condiciones para violentar a las mujeres Indígenas. Nuestro colectivo de académicas y lideresas MéxicoCanadá ha llegado a concluir que la mayoría de las bases de datos utilizan metodologías y lógicas que no corresponden a los contextos, percepciones, experiencias y conocimientos de las mujeres Indígenas.

Un elemento importante señalado en nuestro conversatorio para la documentación fue el tema de la identidad que juega un rol diferenciado en la labor de visibilización de las violencias en contra de las mujeres Indígenas. En el contexto mexicano cuando los observatorios trabajan con notas de prensa local y regional se enfrentan a la limitación de que las narrativas periodísticas amarillistas pocas o escasamente describen o hacen señalamientos sobre la condición social, étnica o racial de las víctimas de feminicidio. A este vacío informativo se suma el hecho de que el reconocimiento de la etnicidad en

\footnotetext{
18 Varios autores como Bonita Lawrence (2004) y Pamela Palmater (2015) han argumentado que es una ley que discrimina a las mujeres Indígenas en particular, en particular las que se han casado con hombres no Indígenas u hombres que no tienen estatus. Esto fue llevado a la corte Suprema de Canadá por Janet Lavelle Corbière en GA vs Lavelle, cuyo
}

México es contextual, donde la autoadscripción juega un rol central así como el manejo de una lengua indígena. En Canadá el gobierno federal tiene datos sobre los pueblos indígenas en base a su propia definición institucional en la 'Ley para Indios', esta definición ha servido para legalmente borrar a varias personas Indígenas quienes han perdido esta identidad debido a los criterios cambiantes para acceder a los derechos limitados que les otorga este estatus. ${ }^{18} \mathrm{Sin}$ embargo, de cierto modo, el estatus permite tener datos desagregados, medir y monitorear los casos de mujeres Indígenas asesinadas o desaparecidas, aunque la posesión del status no sea garantía de respeto a sus derechos humanos fundamentales. Siguiendo este argumento, añadiremos que en el caso de mujeres Indígenas sin estatus que han sido asesinadas o desaparecidas están doblemente silenciadas por la numeralia oficial.

La falta de reconocimiento políticoidentitario opera también como mecanismo de silenciamiento e invisibilidad. En el contexto mexicano Patricia Torres argumenta que “... el colonialismo logra atravesar las instancias federales y cualquier institución de gobierno, de tal forma que desvaloriza la palabra de las mujeres Indígenas, no

caso perdió pero fue la base para las enmiendas introducidas en 1985 en el caso GA vs. Lovelace in 1981, a través de la Acta C-31 (Bill C-31). Disponível em: https://www.thecanadianencyclopedia.ca/en/article/jeannette -vivian-lavell. Accesso 21 jun 2020. 
reconociéndolas como sujetas de derechos, con reclamos y demandas propias. Cuando una mujer Indígena se presenta a poner una denuncia se le rechaza y se le invalida. Lo mismo ocurre con la voz de mujeres Indígenas que no tenemos un grado académico por instituciones reconocidas, pareciera que tampoco estamos diciendo nada (Torres, presentación en el congreso del LASA, 16 de mayo del 2020). Es por estas razones que el producir conocimiento sobre la violencia que aqueja a las mujeres Indígenas es una tarea que debe hacerse -desde el seno de experiencia de vida- con un claro compromiso de poner en práctica métodos alternativos y propios, en concierto con otros colectivos que estén desarrollando y enfrentando retos similares.

\section{Visibilizar, contabilizar y sanar las violencias: metodologías con ética y respeto}

Los retos de la documentación de las violencias están en el centro de nuestros diálogos de colaboración Canadá-México. Desde distintos colectivos enfrentamos la tarea de experimentar distintas metodologías que nos permitan integrar interseccionalmente varios elementos de análisis. En esta sección queremos hacer énfasis en la complejidad política $\mathrm{y}$ académica de resolver estos retos. Las preguntas que guían esta sección se centran en narrar el origen de los colectivos que componen la colaboración y con qué propósito cada quién lo está haciendo desde el marco de sus organizaciones.

\section{CONAMI-ECG}

En respuesta a las formas institucionales y sociales de silenciamiento y deshumanización de las mujeres indígenas, la Coordinadora Nacional de Mujeres Indígenas de México (CONAMI) ha desarrollado desde hace 23 años un fuerte activismo para movilizar y colocar discursos antidiscriminatorios a través de varias iniciativas. CONAMI es una red de organizaciones mixtas y de mujeres Indígenas de origen rural y urbano que surge el 9 de agosto de 1997 con el objetivo de posicionar la voz de las mujeres organizadas de manera autónoma, para interpelar al movimiento Indígena nacional, al Estado mexicano y a la sociedad en su conjunto. Durante el sexenio 2006-2012 en el cual fue presidente de México Felipe Calderón Hinojosa, se decretó la guerra contra el narcotráfico, lo que tuvo como resultado una escalada de violencia nunca antes vista. Debido a que en el contexto de la lucha contra el crimen organizado las vidas de hombres y mujeres Indígenas parecían no importar, en el 2013 CONAMI inició la documentación de violencias a través 
de la iniciativa llamada Emergencia Comunitaria de Género (ECG). ECG nació para documentar todo tipo de violencias incluyendo las que se generan por la imposición de megaproyectos, la presencia del crimen organizado, la violencia institucional y hasta una de las expresiones más crudas: el feminicidio. En ese momento aún no estaba tipificado el feminicidio como tal, siendo el movimiento feminista y las académicas quienes se movilizaron logrando colocar la violencia feminicida en la agenda pública. Sin embargo, "las mujeres Indígenas sentíamos qué a pesar de los esfuerzos de las organizaciones, de la academia y del movimiento feminista, aún éramos invisibles en la cifras que se reportaban sobre feminicidio y la violencia de género" (DEL JURADO y DON JUAN, 2019, p.9).

Emergencia Comunitaria de Género es una iniciativa de activismo digital que tiene vida en una página de Facebook con el mismo nombre para que las integrantes de la CONAMI publiquen las noticias que circulan en medios electrónicos sobre las diversas violencias que enfrentan las mujeres Indígenas. Este ejercicio es muy importante pues documenta las distintas expresiones de violencia étnico-genéricas e institucional (como por ejemplo el maltrato recurrente a mujeres Indígenas en el sistema de salud) que se intersectan con expresiones locales y más crudas como el feminicidio, la desaparición forzada y la trata de personas. En diversas ocasiones se ha cuestionado e invitado a enfocar los esfuerzos de CONAMI con la documentación en el feminicidio, tal como lo hacen la mayoría de los observatorios feministas, para realizar análisis comparativos e interseccionales y con ello avanzar en la construcción de políticas públicas generales que detengan los feminicidios al ser acordes a los diversos contextos que CONAMI enfrenta. Pero es también interés de CONAMI seguir el camino propio por la erradicación de las violencias desde las construcciones epistemológicas y metodológicas colectivas que generen formas de prevención, atención, sanación y procuración de justicia más allá del Estado. Es por ello que para CONAMI es imperativo seguir documentando aquellas condiciones creadas por el sistema de poder que afectan desproporcionadamente a las mujeres Indígenas. La CONAMI considera que las variables e indicadores que han sido utilizados en los observatorios feministas no toman en cuenta elementos contextuales de las realidades indígenas y rurales, elementos que escapan a la media nacional, o a la universalización de la experiencia de la violencia de género. Como ya se ha mencionado, la reproducción sistemática de la pobreza, la racialización y la discriminación de los cuerpos de las mujeres en "ciertos territorios" nos habla de determinadas expresiones de violencias 
interseccionales que es necesario no perderlas de vista. Para esto, CONAMI está consciente del gran reto que implica diseñar la metodología de recolección, análisis e interpretación de un abanico de datos proveniente de diversos contextos; pero también creemos que de la riqueza de información que se generará, respalda de manera potente el activismo y trabajo realizado hasta hoy.

Patricia Torres destaca que para CONAMI ha sido un reto crear medios específicos para dimensionar las violencias en contextos locales contra de las mujeres Indígenas; por ejemplo, cuando se analiza cómo el narcotráfico ha trastocado el tejido comunitario, y por qué sus impactos destructivos no han recibido una atención prioritaria por parte de ningún gobierno (HERNÁNDEZ, 2019). Las violencias que las mujeres Indígenas viven en sus territorios se traslapan, se concatenan y conectan con otras lógicas de despojo, y de poder. Saber cuál es el peso definitorio o más significativo es una tarea pendiente por realizar. La herramienta de investigación creada por la ECG nos ha permitido empezar a monitorear de la violencia en varios territorios Indígenas -ya que lo hacemos entre varias- y nos ha ayudado a conocer más sobre nuevos tipos de violencias en contra de las mujeres Indígenas:
"Para nosotras [la creación de la base de datos] representaba esa oportunidad de generar nuestras propias estrategias de monitoreo, de sistematización, de creación de variables estadísticas que permitieran hacer un análisis cualitativo, para posteriormente postular algunas propuestas, ya fuera a organismos internacionales, a algunas dependencias en México y para atender la parte comunitaria." (Torres, presentación en el congreso de LASA, mayo 16 2020)

A menudo, estas formas contextuales y propias de hacer investigación se nombran metodologías "artesanales" por, supuestamente, carecer de la rigurosidad científica académica y la estadística, pero sí representan para nosotras un medio para trabajar en conjunto y hacer más accesible la tarea de recopilar datos y notas periodísticas que son basadas en el conocimiento de nuestras comunidades y podemos detectar los marcadores identitarios que no son evidentes a las personas no-Indígenas. Esta es nuestra iniciativa de investigación que responde al proceso político-organizativo nacional y las lógicas de trabajo local de las integrantes de Conami, y queremos seguir estableciendo diálogos colaborativos con la academia que sean respetuosos de nuestras propias apuestas políticas y maneras de hacer investigación y usar la información. Tal como lo señala Norma Don Juan: 
"Hacer la documentación es trabajar contra el racismo y la discriminación estructural institucionalizada $\mathrm{y}$ quitarnos de ese lugar como sujetas de atención, personas vulnerables que por lo tanto no toman parte de las decisiones para combatir las violencias. El producir los datos, el definir qué y cómo se va a hacer implica potenciar nuestro activismo porque nos permite profundizar en las reflexiones conceptuales $\mathrm{y}$ políticas, respaldar con datos duros nuestros discursos, generar propuestas de atención integral. (Don Juan, presentación en el congreso de LASA, 16 de mayo, 2020).

Una de las misiones de CONAMI es buscar el reconocimiento de la articulación de conceptos e ideas desde nosotras. Esto significa cuestionar el colonialismo epistemológico y hablar desde nuestras palabras para poner en alto lo que decimos y hablamos, y que nuestras ideas y participaciones sean reconocidas como válidas.

\section{Baawaating- IWACTF}

Comentando sobre el contexto canadiense mencionaremos el trabajo de las mujeres Anishinaabe del colectivo IWAVTF de conformación reciente - han sido muy visibles en organizar la Marcha conmemorativa de mujeres y niñas Indígenas desaparecidas y asesinadas que se realiza cada 14 de febrero en todo Canadá. La desaparición $\mathrm{y}$ asesinato de mujeres indígenas es un asunto que ha tomado muchas décadas para remontar el desinterés público, y poco ha ido tomando una resonancia nacional como resultado de la acción insistente de distintas organizaciones de mujeres indígenas en el país. En el contexto de la ciudad de Sault Ste. Marie al norte de Ontario ubicada en el territorio conocido como Baawaating, las mujeres Indígenas Anishnaabe han orquestado la resistencia local. La IWAVTF está compuesta por mujeres jóvenes y mayoras, activistas $\mathrm{y}$ académicas, que cumplen diferentes roles de guía, enseñanza, cuido en temas sensibles para la comunidad. Colectivamente realizan esta labor que viene desde las visiones, las cosmovisiones, los entendimientos - del problema y problemática - de las mujeres Indígenas Anishinaabe. Este trabajo ha tenido mucha resonancia en la región porque hasta la fecha, no se había organizado la atención al tema desde las bases - por un grupo conformado estrictamente por mujeres Indígenas - que lideraron estos procesos.

En los documentos organizativos del colectivo IWAVTF se señala que su misión es trabajar por una comunidad que no tolere la violencia en contra de las mujeres Indígenas (IWAVTF 2018). Es por esto que se ha enfocado desde su creación en el año 2017 la importancia de realizar investigaciones que sean participativas, culturalmente apropiadas y basadas en las necesidades de la comunidad con el objetivo de profundizar nuestra 
comprensión de las causas sistémicas y fundamentales que hacen que las mujeres Indígenas sufren tasas desproporcionadas de violencia contra ellas. El propósito es proveer una fuente de información que honren la memoria de las desaparecidas y asesinadas del territorio de Baawaating.

Vivian Jiménez-Estrada remarcó que, en términos de contabilizar el número de mujeres Indígenas afectadas, usualmente se contabilizan las muertes, los asesinatos o desapariciones como que fueran un dato más y no el respeto que se merecen estas historias:

"Este tipo de deshumanización ha sido parte del porqué no se ha creído que es útil crear bases de datos, aunque en términos políticos es una herramienta necesaria para demostrar la naturaleza sistémica de las desapariciones y muertes de mujeres Indígenas" (JiménezEstrada, presentación en el congreso de LASA, 16 de mayo, LASA 2020)

Es importante recordar que las historias de estas mujeres violentadas son sagradas y por lo tanto, cada vez que esa historia se cuenta y se vive se debe de honrar $\mathrm{y}$ recordar porque nuestro compromiso es colaborar en este trabajo para prevenir más violencias; ese es el compromiso que nosotras hemos adquirido y el reto metodológico es poder recordar y honrar que somos seres humanos (LUCCHESI, 2019). Ese compromiso de co-crear estos datos para no crear otra violencia en contra de la memoria de las mujeres asesinadas es clave en nuestro trabajo colectivo. Lo hacemos de tal manera para no replicar el daño $y$ nuestras metodologías reflejan esto e incluyen utilizar la conexión con nuestros ancestros por medio de nuestra espiritualidad:

La ceremonia enfoca la atención para que la atención se convierta en intención. Si se unen y profesan algo ante su comunidad, lo responsabiliza "(WALL KIMMERER, 2013, p.249)

Esta enseñanza reafirma los consejos de nuestras Mayoras en Baawaating, específicamente una de nuestras Mayoras Anishinaabe nos compartió que:

"Necesitamos fortalecer nuestra relación con cada una de nosotras y continuar compartiendo nuestro conocimiento, nuestros problemas y también nuestras propias soluciones ... ya sea cara a cara o virtualmente. Si queremos nutrir nuestra relación debemos de continuar hablándonos. Hay varias mujeres que no pudieron estar ahí pero que nos pueden apoyar pero también necesitamos apoyarlas a que reconozcan que ellas también tienen lo necesario para crear cambios. Es importante tener ceremonia como lo hicimos en este encuentro, y esta es la mejor manera de ser guiadas (por los ancestros) (Taller en Algoma University, 29 de abril 2019).

La espiritualidad es importante para los pueblos Indígenas y no se puede dejar a un lado dentro del proceso de investigación. Metodológicamente, el trabajo que se hace 
para apoyar las luchas y resolver problemas en colaboración con, y desde las perspectivas Indígenas, es sumamente importante (JIMÉNEZ-ESTRADA 2005; WILSON 2003 y 2008; KOVACH 2010). Es parte de un proceso de descolonización epistémica dentro del producción del conocimiento y de trabajar en colaboración desde y para los Pueblos Indígenas.

\section{La interpelación y lo político en nuestros diálogos a distintas escalas}

Una parte muy importante del trabajo de incidencia que realizan nuestras organizaciones tiene que ver con el ejercicio de interpelar al Estado recurriendo al marco internacional de derechos humanos a fin de establecer diálogos informados y críticos respecto a sus políticas de gobierno antiviolencia feminicida y violencia de género. Nos preocupa hacer llegar mensajes claves que ayuden a revelar las fallas, lo que está incompleto o no debidamente observado. Nos ha servido discutir y contrastar los marcos normativos nacionales -tanto el mexicano

\footnotetext{
${ }^{19}$ La Alerta de Violencia de Género contra las Mujeres (AVGM) es un mecanismo implementado por el gobierno de México con el fin de «enfrentar y erradicar la violencia feminicida en un territorio determinado. Abarca diversas acciones, como protocolos de investigación sobre feminicidios y programas destinados a la prevención, así como reformas para eliminar la desigualdad en la legislación y política pública. La AVGM se estableció en 2007 con la creación de la Ley General de Acceso de las Mujeres a una Vida Libre de Violencia. De acuerdo con el Artículo 25 de
}

como el canadiense- en lo que respecta a los mecanismos y protocolos de prevención y sanción de la violencia extrema y de género.

Para el caso canadiense, las compañeras de Bawaating han estado trabajando en el marco de la investigación nacional sobre el asesinato y desaparición de mujeres Indígenas (IMMIWG, 2017-2019) del gobierno de Justin Trudeau (IMMIW, 2019); y para el caso mexicano, como ya se mencionó, hay una preocupación muy sentida por observar el desarrollo y efectividad del mecanismo de la Alerta de Violencia de Género contra las Mujeres (AVIGM). ${ }^{19}$ En función de estos dos marcos nacionales de interpelación nuestras iniciativas dialogan y en esta sección explicaremos las maneras y objetivos de interpelar a la estructura de poder que excluye y tutela a los Pueblos Indígenas en general, y a las mujeres en particular.

Vivian Jiménez-Estrada explica que el proceso de interpelación en la experiencia del colectivo del Baawaating al norte de Ontario tomó varios caminos. La inquietud para organizarse inició en el 2015 cuando se empezó a gestar una visibilización pública de la violencia contra mujeres; ello sucedió

esa Ley, la declaratoria de alerta de género corresponde al gobierno federal por medio de la Secretaria de Gobernación. Este mecanismo se activa para alertar a las personas pertenecientes a instancias gubernamentales y a la población en general sobre la urgencia de detener los feminicidios, el acoso callejero, laboral, escolar o doméstico, la discriminación y la violencia que viven las mujeres mexicanas, con el propósito de garantizar una buena calidad de vida libre de desigualdades. 
cuando el feminicidio de Loretta Sanders, una estudiante Inuk que estaba realizando una tesis sobre las mujeres Indígenas asesinadas y desaparecidas y quien fue asesinada por dos personas blancas que le debían dinero por rentarles cuartos en su departamento, los estudiantes de la universidad mostraron la inquietud de porqué no hacer nada ante estos hechos y preguntarse porqué la academia no está poniendo atención en este agravio. En ese entonces muchas nos preguntamos qué estábamos haciendo sobre la visibilización de la violencia contra las mujeres Indígenas. En los medios de comunicación resonaban muchos casos como el de Loretta, quien al principio recibió mucha atención por parte de la policía y medios de comunicación debido a que su tez era blanca. Sin embargo, como reportado por varios medios de comunicación y durante la Investigación nacional de mujeres Indígenas asesinadas y desaparecidas, el momento que la madre aclaró que Loretta era Inuk y no blanca, la asistencia para encontrarla y la perseverancia para llevar a juicio a los acusados del feminicidio disminuyó (BARRERA, 2017).

En Baawaating, la IWAVTF conoce de varios casos, de familiares que llegan a la policía buscando ayuda para encontrar o salvar a sus madres, tías, primas, sobrinas, hermanas, hijas - pero no hay confianza. No les prestan atención y no las atienden. Ahí es donde entra en juego el prejuicio y el racismo sistémico, que lo que hace es desestimar situaciones de peligro. La respuesta de la policía a denuncias de mujeres desaparecidas es a menudo de esperar, que seguro está afuera, teniendo sexo con alguien, y si es sexo-servidora pues es más la desidia en buscarle. Como ya se explicó anteriormente, esta desvalorización y actuación se basan en el mito de la mujer Indígena como híper-sexual y disponible, lo cual representa un gran bloqueo para acceder a la justicia y que se haga justicia.

Por esta razón, parte de las 231 recomendaciones del informe final de la investigación nacional de las mujeres Indígenas desaparecidas y asesinadas (GOBIERNO DE CANADÁ, 2019) incluye interpelación a sistemas de educación para destruir estos mitos y estereotipos sobre las mujeres Indígenas e incluye a personas de géneros y orientación sexual diversas porque apunta a responder y desmontar los bloqueos recurriendo a la historia de saber qué fue lo que pasó, lo que pasó que da sentido a la problemática de discriminación actual. También se interpela a la policía porque ha habido un sin fin de reportes $y$ notas periodísticas hasta la fecha sobre la falta de protección y atención que se les brinda a estos casos de mujeres desaparecidas. Además, las actitudes racistas, sumadas a la reciente historia de despojo de niñas y niños durante la época de las escuelas residenciales y la década de los 60s han tenido y siguen 
teniendo efectos negativos en la comunidad Indígena. Ha sido también problemático que se les ha despojado a las comunidades Indígenas acceder y aplicar sus propias maneras de hacer justicia. En Canadá, las 231 recomendaciones del informe final ya mencionado (Gobierno de Canadá) respaldan el trabajo que se realiza para concientizar y proveer educación sobre el tema al público en general. También apoya el trabajo legal que se realiza en Baawaating para identificar qué debe hacerse con la policía. En resumen, todo esta incidencia política es para desmantelar esos imaginarios que deshumanizan a las mujeres y pueblos Indígenas.

De manera similar, el tratamiento de la violencia ha sido para CONAMI una constante en lo político y académico. Las lideresas de CONAMI han sido enfáticas en movilizar sus opiniones críticas a las políticas de intervención anti-violencia feminicida, ya que implementa mecanismos para la formulación de diagnósticos y documentos peticionarios de la declaración de las Alertas de Género en municipios donde se sospecha que hay alzas en los índices de homicidios femeninos. Los instrumentos y encuestas comúnmente aplicados no son adecuados para recabar información de hechos ocurridos en zonas rurales e Indígenas, aunado al hecho de que los equipos de trabajo fallan en incorporar investigadores locales e indígenas, y/o no consultan a autoridades y actores comunitarios a fin de tener una apreciación más contextual. Tanto CONAMI como otros colectivos de defensoría de derechos humanos de mujeres Indígenas toman distancia de formas de trabajo investigativo que, por denunciar la pandemia feminicida contra las mujeres frente al Estado, poco se detienen a trabajar con interpretaciones locales de eventos que pueden variar de maneras muy significativas y que escapan a la unidimensional explicación de la muerte de mujeres por el patriarcado. En específico argumentamos que la comprensión de los contextos y las dinámicas locales a través de la narrativa de los y las actores es sustancial para conocer la particularidad de la experiencia de violencia en la cotidianidad de mujeres Indígenas que sufren de discriminaciones de largo aliento.

La CONAMI es integrante desde hace casi 23 años del Enlace Continental de mujeres Indígenas de las Américas (ECMIA) tiempo en el cual ha aprendido a hacer propias las necesidades y demandas de todas las mujeres Indígenas de la región, a promover sus necesidades y derechos en contextos transnacionales, reconociendo también que las estrategias de dominación y explotación así como el feminicidio son procesos globales que se deben combatir más allá de las fronteras geopolíticas nacionales impuestas. Históricamente, las fronteras geopolíticas han servido entre otras cosas para dividirnos como 
pueblos y comunidades, un ejemplo es la frontera de México-EUA que divide a nuestros hermanos Yaquis que viven en Sonora y en Arizona, teniendo que hacer un esfuerzo extra para no perder el sentido de humanidad, hermandad y comunidad; por otro lado los estados nacionales argumentan ante mecanismos multilaterales que sus acciones restrictivas ante los derechos humanos y el cierre de sus fronteras es por la defensa de su soberanía, seguridad y unidad nacional limitando el cuestionamiento a sus políticas.

En los últimos 40 años a nivel internacional se han creado declaraciones y mecanismos de protección a los derechos humanos de las mujeres y pueblos Indígenas, en estos momentos de crisis global es imperativo fortalecer los mecanismos multilaterales de la ONU que su labor facilite la exigibilidad de justicia y respeto a los derechos humanos impulsando políticas globales para la concientización, movilización y erradicación de las violencias que no estén limitadas por las fronteras geopolíticas de los Estados nacionales.

Norma Don Juan nos relata como en la CONAMI

"No podemos estar hablando de victimas válidas o inválidas al prejuzgar y dejar al margen de la protección y justicia a mujeres que tienen alguna relación con el crimen organizado, que es un fenómeno al que no se le a prestado atención y que victimiza una y otra vez a las mujeres [...] también interpelamos a la sociedad Indígena y no Indígena, las violencias contra las mujeres son violencias contra nuestros pueblos, son violencias genocidas y debemos movilizarnos todos." (Don Juan, presentación en el congreso LASA, presentación en el congreso de LASA, 16 de mayo 2020)

Este mensaje de interpelar a la sociedad Indígena y no-Indígena resuena con el trabajo de la IWAVTF a nivel local debido a que se está realizando trabajo con varias entidades para coordinar acciones que promuevan no solamente la creación de una base de datos con pertinencia sino también trabajar con las organizaciones que atienden a las mujeres Indígenas que viven o pasan por Baawaating y sensibilizarlos sobre las necesidades y contextos históricos necesarios para poder brindar atención adecuada a sus situaciones. De esta manera es sumamente importante el trabajo que se realiza con la CONAMI debido a que la IWAVTF no tiene una trayectoria de incidencia política o trabajo en red a nivel internacional y por esta razón se siente muy afortunada de poder aprender de sus hermanas del Sur. Finalmente, queda claro que estas relaciones Norte-Sur entre organizaciones de mujeres Indígenas contienen un gran potencial transformador que harán la diferencia desde sus organizaciones y pueblos. 
Conclusiones: los retos al futuro y la agudización de condiciones de violencia

Las reflexiones de este artículo están basadas en una mesa redonda preparada para el Congreso de la Asociación de Estudios Latinoamericanos llevada a cabo el 16 de mayo del 2020. En aquella ocasión compartimos la experiencia de activistas y académicas de México y Canadá que hemos estado participando en un proyecto de colaboración, diálogo y encuentro sur-norte sobre violencias contra mujeres Indígenas de las Américas y sus formas de documentación y visibilización. El punto de análisis parte de una crítica hacia la producción del conocimiento sobre violencia contra mujeres Indígenas, y las estrategias culturalmente sensibles para visibilizar y comprender las experiencias de violencia colonial y patriarcal infligida contra mujeres Indígenas en los territorios de la "Isla Tortuga" como se le dice a Norteamérica y en Abya Yala en general. Los retos residen en encontrar soluciones que se basan en los conocimientos y experiencias de las mujeres Indígenas, centradas en la comunidad, para enfrentar el aumento exponencial de la violencia cometida contra las mujeres indígenas en Canadá y México. Esto es clave para ir más allá de las políticas generalistas anti-violencia de género que no han tomado en cuenta las recomendaciones de los pueblos indígenas a fin de incorporar la violencia colonial y estructural en sus mecanismos y mecanismos preventivos.

Cuando nos encontramos virtualmente en el marco de LASA estamos recién tomando consciencia de los nuevos escenarios de trabajo en estos tiempos del coronavirus (COVID-19). Para ese momento teníamos ya un sentir de los impactos en la salud de la población marginal con la que trabajamos, los gobiernos en Canadá y México han reconocido que las condiciones en las cuales la mayoría de Pueblos Indígenas viven agudizan emergencias de salud, en particular para las mujeres y personas sufriendo violencias en casa o en sus sitios de empleo. En entrevista con la red de comunicación Indígena APTN el 20 de marzo del 2020, el Ministro de Servicios para pueblos Indígenas de Canadá, Marc Miller, dijo que:

Los pueblos Indígenas son más vulnerables que los no Indígenas. Vimos esto en H1N1 y vimos esto durante el SARS. Hemos aprendido de esos eventos, pero la realidad sigue siendo que los pueblos Indígenas en Canadá experimentan más hacinamiento, una mayor carga de enfermedades crónicas, $\mathrm{y}$ algunos viven en partes muy remotas y aisladas de este país. (APTN, 2020, 20 de marzo)

Como ya establecimos anteriormente, las reservas están localizadas en áreas remotas 
$\mathrm{y}$ en tierras menos valiosas, a menudo fuera del territorio tradicional de los Pueblos Indígenas. Es el mismo escenario en Canadá y en México. Sin embargo, debido a las restricciones de cuarentena, la vida comunal y las maneras propias de curación y de cuidado han sido suspendidas para proteger a sus ancianos y comunidades. Es una precaución necesaria, pero para muchos, es un recordatorio de cuándo se prohibieron las actividades culturales y para el trabajo que se venía haciendo en Baawaating, es una barrera para proveer servicios y espacios para poder abordar el tema de la violencia con la población afectada. La IWAVTF ha tenido que posponer sus actividades de curación y sin embargo estar atentas a los llamados y necesidades de trabajadoras sexuales, y personas que no tienen un hogar en donde pasar la cuarentena.

El informe del Observatorio Canadiense de Feminicidio y Justicia de la Universidad de Guelph (2019) identifica que cuando se ha reconocido algún victimario, el 91\% son hombres. Dado que el hogar es el lugar más peligroso para las mujeres y las niñas, con un 53\% asesinado por parejas masculinas y un $13 \%$ asesinado por otros miembros masculinos de la familia que 38 por ciento de los acosadores son sus parejas, o casados legalmente (36 por ciento) es

\footnotetext{
${ }^{20} \mathrm{https}: / / \mathrm{www}$. femicideincanada.ca/about/trends
}

alarmante para muchas tener que estar en estado de emergencia junto a su acosador. ${ }^{20}$ El informe especial de la relatora especial de las Naciones Unidas sobre la violencia de género contra la mujer, sus causas $\mathrm{y}$ consecuencias, indica que las llamadas para denunciar \#VAWG han aumentado un $60 \%$ y las solicitudes para refugios para mujeres se han duplicado. ${ }^{21}$

Este nuevo contexto generado por la pandemia nos hace pensar en el reto metodológico que implica la labor de documentación cuando la cobertura de los medios y la atención están centrados en atender la emergencia sanitaria dejando en un segundo plano la violencia feminicida que a pesar de que incrementa y se recrudece se deja de registrar por parte de los medios de comunicación, aunado a esto las defensoras no pueden movilizarse por las medidas sanitarias, por que los recursos económicos escasean y por que el trabajo de cuidado de la familia recae en ellas reduciendo el tiempo que pueden destinar a su activismo. El COVID está impactando nuestro trabajo de visibilización y documentación de la violencia de género, ya que toda la agenda pública se concentra en el COVID. Toda la información del gobierno que genera y la cobertura de los medios de comunicación es sobre el COVID en las cifras, minuto a minuto. Esperamos que ello tenga un

21

https://secureservercdn.net/198.71.233.51/ijf.9f0.myftpuploa d.com/wp-content/uploads/2020/07/Las-dos-pandemias.pdf 
declive hacia necesidades de información que sean más profundas y contextuales. Es en este momento que vemos necesario replantear las formas en la que hacemos investigación y documentación, así como colaboración y acompañamiento investigativo $\mathrm{y}$ activista sobre violencias contra mujeres Indígenas. También las formas de ejercer la violencia se han reconfigurado, pero eso no implica que hayan bajado las cifras de feminicidios contra mujeres Indígenas, tanto en Canadá como en México. Los colectivos feministas y de mujeres Indígenas coinciden en que los feminicidios no han disminuido, que las desapariciones forzadas continúan, que los defensores de derechos territoriales y recursos naturales siguen siendo diezmados, y que los refugios para mujeres golpeadas violencia familiar siguen requiriendo de estar disponibles.

Con la pandemia, la movilización física en las calles está siendo prohibida, lo cual ha forzado a la resistencia a desaparecer de la esfera pública, siendo los medios de comunicación electrónicos casi la única vía de acceso a la participación e incidencia política, pero no todas las mujeres Indígenas tienen acceso a las tecnologías de la comunicación, visibilizando el ensanchamiento de las brechas digitales como un factor de exclusión para un sector importante de mujeres Indígenas que se ven afectadas en el acceso a atención y servicios básicos, acceso a la protección y justicia, a denunciar públicamente las violencias que enfrentan así como para la documentación e incidencia públicas.

También, la pandemia ha venido a invisibilizar la violencia contra defensores y defensoras del territorio que siguen siendo asesinados, ya sea en los territorios o en sus casas. Muchas de las defensoras hacen su labor activista financiada con sus propios bolsillos además de que tienen que general sus propios ingresos en medio de la pandemia. Muchas de nosotras destinamos recursos propios al servicio de internet. Eso tiene un claro impacto en la documentación a través de las redes porque ya no tenemos a la disposición del recurso del "tiempo" para hacerlo, porque hay ahora una pobreza del tiempo. Ya no tenemos el tiempo que ocupamos trabajar en esto, para intercambiar, para ir procesando, para ir documentando. Entonces sí, el COVID -19 está impactándonos, porque nos deja al margen de la información e invisibiliza lo que pasa con nosotras.

$$
\text { Como comentario final, }
$$
mencionamos que hace más de tres años hemos estado trabajando para encontrar los medios y los recursos necesarios para dialogar, ya sea presencial o virtualmente. Bajo el entendido que documentar las violencias de mujeres indígenas es una tarea compleja, no sólo en términos conceptuales y metodológicos, sino también humanos $\mathrm{y}$ 
éticos. Aplicar a fondos ha sido una estrategia para financiar los espacios en los cuales hablamos y esclarecemos, que nos ayudan a esclarecer poco a poco los distintos niveles de análisis. Y sobretodo, encontrar lenguajes comunes y limar asperezas, tratar de establecer diálogos más nítidos y sinceros entre la academia y el activismo de mujeres Indígenas. Las relaciones de poder y los espacios privilegiados que algunas de nosotras tenemos con respecto al trabajo de las lideresas Indígenas es difícil de sortear. Pero reconocemos que en este trabajo hemos construido una solidaridad que nos jala a seguir construyendo alianzas, y a legitimar las distintas voces que teorizan las violencias de género, y a criticar desde la academia las formas en cómo el feminismo se "hace la terminología" y aplica conceptos que no reflejan la experiencia de vida social desde distintos lentes. Esperamos que este material, construido colectivamente, haya contribuido a la reflexión comparativa, Indígena e interseccional sobre las metodologías cuantitativas y cualitativas- para documentar las violencias extremas y feminicidios en México y Canadá.

\section{Referências bibliográficas}

\author{
ABORIGINAL PEOPLE'S NETWORK \\ (APTN). Indigenous Services Minister \\ explains COVID-19 funding for Indigenous \\ communities. APTN youtube channel.
}

Disponível em: https://www.youtube.com/watch?v=DlEgQA gKUiI. Acceso em: 12 maio 2020.

AGUIRRE BELTRÁN, Gonzalo. Regiones de refugio : el desarrollo de la comunidad y el proceso dominical en el mestizo América. MÉXICO: INPI. 1967.

ALTAMIRANO-JIMENEZ, Isabel. Indigenous Encounters with Neoliberalism. Place, Women, and Environment in Canada and Mexico. BC: UBC Press. 2013.

ASOCIACIÓN CANADIENSE DE ESTUDIOS LATINOAMERICANOS Y DEL CARIBE (CALACS). Violencia contra las mujeres Indígenas de las Americas. Informe Final del Foro Virtual. Febrero 6 Marzo 10, 2017. Disponível em: https://canlatam.org/sites/canlatam.org/files/forum/media/acelc_foro_virtu al_violencia_contra_mujeres_indigenas_de_1 as_americas_.pdf. 2017. Acesso em: 28 abr 2020.

BARRAGAN, Almudena, Rodriguez, Darinka. Las llamadas por violencia de género en México aumentan $60 \%$ durante la cuarentena. El País, Abril 3 2020. Disponível em:

https://verne.elpais.com/verne/2020/04/02/me xico/1585780887_471083.html. Acesso em: 28 abr 2020.

BONFIL, Paloma, De Marinis, Natalia, Rosette, Patricia y Martínez, Raul (eds.) Violencias de Género contra las Mujeres en Zonas Indígenas de México. Mexico: SEGOB/CIESAS/CONAVIM. 2017

BOURGEOIS, Robyn. "Generations of genocide: the historical roots of missing and murdered indigenous women and girls". In Anderson, Kim; Campbell, Maria; Belcourt, Christi (coords.) Keetsahnak: Our Missing and Murdered Indigenous Sisters. Calgary, University of Alberta Press, pp. 65 - 88, 2018. 
BOURGEOIS, Robyn. Race, Space and Prostitution: The Making of Settler Colonial Canada. 30 Canadian Journal of Women and Law, 371-397.

BRADFORD BURNS, Edward. The Poverty of the Progress. Latin American in the Nineteenth Century. California: University of California Press. 1983.

CANADIAN FEMICIDE OBSERVATORY FOR JUSTICE AND ACCOUNTABILITY (CFOJA). Calling femicide Understanding gender-related killings of women and girls in Canada 2018. Canada: Guelph University. 2019.

\section{CONSEJO NACIONAL DE}

EVALUACIÓN DE LA POLÍTICA DE DESARROLLO SOCIAL. La pobreza en la población indígena de México. México, DF: CONEVAL, 2018

COULTHARD, Glen Sean. Red Skin, White Masks: Rejecting the Colonial Politics of Recognition. Minneapolis: University of Minnesota Press. 2014.

CRENSHAW, Kimberly. Mapping the Margins: Intersectionality Identity Politics, and Violence against Women of Color. Stanford Law Review 43 (6), p 12411299, 1993.

DATA CÍVICA. Claves para entender y prevenir los asesinatos de mujeres en México. México. 2019. Disponível em: https://datacivica.org/assets/pdf/claves-paraentender-y-prevenir-los-asesinatos-demujeres-en-mexico.pdf

DEL JURADO, Fabiola, Don Juan, Norma. "Emergencia Comunitaria de Género: Respuesta de las mujeres Indígenas a las múltiples violencias y el despojo del territorio". Revista Ichan Tecolotl, ano 30, n. 321, (p. 9), feb. 2019. Disponível em: https://ichan.ciesas.edu.mx/emergenciacomunitaria-de-genero-respuesta-de-lasmujeres-Indígenas-a-las-multiples-violencias- y-el-despojo-del-territorio/. Acceso abr 12 2020.

DON JUAN, Norma. Retos para documentar el feminicidio en zonas Indígenas en México y Canadá desde una perspectiva interseccional. Presentación el 16 de mayo, LASA 2020.

ENDIREH. Encuesta Nacional sobre la Dinámica de las Relaciones en los Hogares 2016. INEGI: Mexico. 2016.

https://www.inegi.org.mx/contenidos/progra mas/endireh/2016/doc/endireh2016_presentac ion_ejecutiva.pdf

ENSADEMI. Encuesta de Salud y Derechos de las Mujeres Indígenas. Instituto de Salud Pública/CDI. México.2008. Disponible en: https://www.insp.mx/produccioneditorial/publicaciones-anteriores-2010/657encuesta-de-salud-y-derechos-de-las-mujeresindigenas-ensademi-2008.html

\section{ENLACE CONTINENTAL DE MUJERES INDÍGENAS DE LAS AMÉRICAS (ECMIA). Violencias y mujeres Indígenas.} Perú: Chirapaq Centro de Culturas Indígenas del Perú, 2013.

ESTRADA, María de la Luz. Aquí matan a las mujeres y no pasa nada. Nexos, n. 484, abr. 2018. Disponível em: https://www.nexos.com.mx/?p=36968. Acesso em: 1 maio 2020.

FIGUEROA ROMERO, Dolores, Hernández, Laura "Justicia de género y autonomía: De la doble mirada de las mayoras a las violencias que no sabemos cómo nombrarlas" En Burguete Cal y Mayor, Araceli, González Pérez, Miguel (eds) Autonomías y autogobierno en territorios indígenas en la America Diversa. Un balance (1990-2020). Quito: Abya yala. En prensa.

FRÍAS, Sonia. Violencias de género en contra de mujeres y niñas indígenas en México en contextos públicos, privados e institucionales. CRIM/UNAM. En prensa, 2021. 
GARCÍA-DEL MORAL, Paulina. The Murders of Indigenous Women in Canada as Feminicides: Toward a Decolonial Intersectional Reconceptualization of Femicide. Signs: Journal of Women in Culture and Society. vol. 43, no. 4. 2018.

GOBIERNO DE CANADÁ. Reclaiming Power and Place: The Final Report of the Inquiry into Missing and Murdered Indigenous Women and Girls. v. 1a, 2019. Disponível em: https://www.mmiwg-ffada.ca/wpcontent/uploads/2019/06/Final_Report_Vol_1 a-1.pdf. Acceso mai 2020.

GUIMONT, Stéphane, Figueroa Romero, Dolores; Jiménez- Estrada, Vivian; Rice, Roberta. Approaching Violence against Indigenous Women in the Americas from Relational, Intersectional and Multi-scalar Perspectives. Canadian Journal of Latin American and Caribbean Studies v. 45, n. 1, pp. 5-24, 2020. Dísponivel em: https://doi.org/10.1080/08263663.2020.16907 81

HENDERSON, William B. Indian Act. 2006. Disponível em:

https://www.thecanadianencyclopedia.ca/en/a rticle/indian-act. Accesso mai 2020.

HERNÁNDEZ CASTILLO, R. A. Las múltiples ausencias de los indígenas desaparecidos en México. En la columna Con-Ciencia. El Grupo de Investigaciones en Antropología Social y Forense (GIASF). Abril.

https://adondevanlosdesaparecidos.org/2019/ 04/25/las-multiples- ausencias-de-losindigenas-desaparecidos-en-mexico/ 2019.

HERNÁNDEZ CASTILLO, Aída. "La guerra contra el narco. Violencia de Género, militarización y criminalización de los pueblos Indígenas". In Sierra, María Teresa, Bastos, Santiago (coords.) Estado y pueblos Indígenas en México. La disputa por la justicia y los derechos. Ciudad de México: CIESAS, pp. $244-267,2017$.
HOLMES, Cindy, HUNT, Sara, \& PIEDALUE, Amy. "Violence, Colonialism, and Space: Towards a Decolonizing Dialogue" ACME: An International EJournal for Critical Geographies. 14(2): 539570, 2014

IIWA; LEAF. IAAW and LEAF continue to seek justice for Cindy Gladue. 2019.

Disponível em: https://www.leaf.ca/iaaw-andleaf-continue-to-seek-justice-for-cindygladue/. Accesso jun 2020.

\section{INDIGENOUS WOMEN'S ANTI-} VIOLENCE TASK FORCE (IWAVTF) Términos de referencia. Documento interno. Sault Ste. Marie, Ontario. 2018.

JACOBS, Beverly. "Response to Canada's Apology to Residential School Survivors". Canadian Woman Studies, v. 26 n. 3/4, pp. 223 $-225,2008$.

JACOBS, Beverly. 2013. Decolonizing Violence Against Women Decolonization, Indigeneity and Society February 13.

Retrieved March 20, 2018

(https://decolonization.wordpress.com/201 3/02/13/decolonizing-the-violence-againstindigenous-women/).

JIMENEZ-ESTRADA, Vivian. "Retos para documentar el feminicidio en zonas Indígenas en México y Canadá desde una perspectiva interseccional". Presentación el 16 de mayo, LASA 2020.

JIMENEZ-ESTRADA, Vivian; Guimont Marceau, Stéphane; Don Juan, Norma, Torres Sandoval, Patricia. "Respuestas a la violencia colonial y de género: Una mirada desde mujeres indígenas y aliadas en México y Canadá" Boletín Ichan Tecolotl. Septiembre. 2019. Disponible en: https://ichan.ciesas.edu.mx/notas-al-ras-dela-tierra/respuestas-a-la-violencia-colonial-yde-genero-una-mirada-desde-mujeresindigenas-y-aliadas-en-mexico-y-canadal

JIMÉNEZ-ESTRADA, Vivian. "El árbol de la vida como metodología de investigación." 
Australian Journal of Indigenous Studies, v. 34, pp. 44 - 52, 2005. Disponível em: https://doi.org/10.1017/S1326011100003951

KAREN, Martin. "Ways of Knowing Ways of Being and Ways of Doing: A theoretical framework and Methods for Indigenous Research and Indigenist Research." Journal of Australian Studies 76:203-14. 2003.

KIMMERER, Robin Wall. "The fortress, the river and the garden: a new metaphor for cultivating mutualistic relationship between scientific and traditional ecological knowledge" En Kulnieks, Andrejs, Longbout, Dan R., Young, Kelly. Contemporary Studies in Environmental and Indigenous Pedagogies: A Curricula of Stories and Places. Rotterdam, The Netherlands: Sense Publishers, pp. 49-77, 2013.

KOVACH, Margaret. Indigenous Methodologies: Conversations, Characteristics and Contexts. Toronto: University of Toronto Press, 2009.

KUOKKANEN, Rauna. "Globalization as Racialized, Sexualized Violence: The Case of Indigenous Women". In International Feminist Journal of Politics 10(2):216- 233, 2008.

LAWRENCE, Bonita. "Gender, Race and the Regulation of Native Identity". Hypatia v. 18, n. 2, Spring, 2003.

LORDE, Audrey. Sister Outsider. Berkeley, CA: Ten Speed Press, 1984.

LUCCHESI, Annita Hetoevèhotohke'e. "Spirit-Based Research: A Tactic for Surviving Trauma in Decolonizing Research". Journal of Indigenous Research. Volume 7 Issue 1 Missing and Murdered Women - SPECIAL ISSUE. 2019

MMIWG Inquiry Hears. CBC Indigenous news, Oct 30, 2017. Disponível em: https://www.cbc.ca/news/indigenous/inquiryns-saunders-1.4378891. Acesso em: 18 jun 2020.
MENDOZA, Jesús. "La comunidad Indígena en el contexto urbano. Desafíos de supervivencia". Ciudad de México: Centro de Estudios Sociales y de Opinión Pública CESOP. Documento de trabajo n. 85, 2010.

MORA, Mariana. "Voces desde los silencios. Mujeres indígenas, seguridad y derechos frente a las violencias en la Montaña de Guerrero.” En SIEDER, Rachel (ed.) Exigiendo justicia y seguridad. Mujeres indígenas y pluralidades legales en América Latina. México: CIESAS, pp. 315-398, 2017.

\section{NATIVE WOMEN'S ASSOCIATION}

(NWAC). What their stories tell us: Research findings from Sisters in Spirit initiative.

Dísponivel em: https://nwac.ca/wpcontent/uploads/2015/07/2010-

What-Their-Stories-Tell-Us-ResearchFindings-SIS-Initiative.pdf. Acceso nov 2019.

OEHMICHEN-BAZÁN, Cristina.

"Adolescentes mazahuas y solidaridad intergeneracional frente a la violencia de género." Anuário Antropológico [Online], II | 2019, posto online no dia 03 dezembro 2019, consultado no dia 05 dezembro 2019. URL: http://journals.openedition.org/aa/3967 ; DOI : 10.4000/ aa.3967

ORGANIZACIÓN DE MUJERES DE LAS NACIONES UNIDAS (ONU mujeres). La Violencia Feminicida en México.

Aproximaciones y Tendencias 1985-2016, 2016. Disponível em: https://www2.unwomen.org/$/$ media/field\%20office\%20mexico/document os/publicaciones/2017/10/violenciafeminicida $\mathrm{mx} \% 2007 \mathrm{dic} \% 20$ web.pdf?la=es\&vs=5302. Acesso em: 20 maio 2020.

PALMATER, Pam. "Shining Light on the Dark Places: Addressing Police Racism and Sexualized Violence against Indigenous Women and Girls in the National Inquiry". Canadian Journal of Women and Law, v. 28, n. 2, pp. $253-284,2015$. 
RAZACK, Sherene. "Gendered racial violence and spatialized justice: the murder of Pamela George". In Razack (coord.) Race, space and the law: Unmapping a white settler society. Toronto: Between the Lines, pp. 121156, 2002.

RAZACK, Sherene. "Gendering Disposability". Canadian Journal of Women and the Law, v. 28, n. 2, pp. 285 -307, 2016.

ROJAS, Ana Gabriela. Etnoporno, la explotación sexual de mujeres indígenas en videos pornográficos en México. $\mathrm{BBC}$ Mundo, 14 de enero 2020. Disponível em: https://www.bbc.com/mundo/noticiasamerica-latina-48699964. Acesso em: 16 de jun 2020.

\section{ROYAL COMMISSION ON} ABORIGINAL PEOPLES (RCAP). The Imposition of a Colonial Relationship, Report of the Royal Commission on Aboriginal Peoples, v. 1, Looking Forward, Looking Back. Ottawa, ON, Canadá: The Commission, 1996.

SCHEPER-HUGHES, Nancy, Bourgois, Phillipe. Violence in War and Peace. An Anthology. Oxford, England: Blackwell Publishing, 2004.

SEGATO, Rita. "Colonialidad y patriarcado moderno: expansión del frente estatal, modernización y la vida de las mujeres". En Espinoza-Miñosom Yuderkys, Diana Gómez Correal, Ochoa Muñoz, Karina (eds.)

Tejiendo de otro modo: Feminismos, epistemología y apuestas descoloniales en Abya Yala. Popayán: Universidad del Cauca, pp. 75-90, 2014.

SEODU HERR, Ranjoo. "Women's Rights as Human Rights and Cultural Imperialism", Feminist Formations, v. 31, n. 3 winter, pp. $118-142,2020$

SIEDER, Rachel, Barrera, Anna. "Women and Legal Pluralism. Lessons from Indigenous Governance Systems in the
Andes". Journal of Latin American Studies. Cambridge University Press. 49, pp. 633-658, 2017.

SMITH, Andrea. Conquest. Sexual Violence and American Indian Genocide. Cambridge MA: South End Press, 2005.

SMITH, Andrea, Ross, Luana. "Native Women and State Violence". Social Justice Rreview, Vol. 31, no. 4(98). Pp- 1-7, 2004.

STATISTICS CANADA. The Daily: Aboriginal Peoples in Canada, Key Results. STATISTICS CANADA, 2017. Disponível em:

https://www150.statcan.gc.ca/n1/en/dailyquotidien/171025/dq171025aeng.pdf?st=jmMcZhtz. Acesso em: 10 maio 2020.

SUPREME COURT OF CANADA. Case in Brief: $R$ v Barton. Disponível em: https://www.scc-csc.ca/casedossier/cb/2019/37769-eng.aspx. Acesso em: 17 jun 2020.

TORRES, Patricia. "Retos para documentar el feminicidio en zonas Indígenas en México y Canadá desde una perspectiva interseccional". Presentación el 16 de mayo, LASA 2020.

WILSON, Shawn. "Progressing towards an Indigenous research paradigm in Canada and Australia" Canadian Journal of Native Education, v. 27, n. 2, pp. 161 - 180, 2003.

WILSON, Shawn. Research is Ceremony: Indigenous Research Methods. Blackpoint, Nova Scotia: Fernwood Publishing, 2008.

WRIGHT, Melissa. "Feminicidio, narcoviolence, and gentrification in Ciudad Juárez: the Feminist Fight." Environment and Planning D: Society and Space 2013, volume 31, pages $830-845,2013$. 